\title{
Development of Abelmoschus esculentus (Okra)-Based Mucoadhesive Gel for Nasal Delivery of Rizatriptan Benzoate
}

\author{
Nitin Sharma ${ }^{1,2 *}$, Giriraj T Kulkarni ${ }^{3}$ and Anjana Sharma ${ }^{2}$ \\ ${ }^{1}$ Jawaharlal Nehru Technological University, Kukatpally, Hyderabad, 500085, India; ${ }^{2}$ Department of Pharmaceutical \\ Technology, Meerut Institute of Engineering and Technology, NH- 58, Baghpat Crossing, Byepass Road, Meerut, 250005, \\ India; ${ }^{3}$ Laureate Institute of Pharmacy, Kathog, Teh. Dehra, Dist. Kangra, 177101, India
}

*For correspondence: E-mail: sharma.nitin0909@gmail.com; Tel: +91 121 2439019; Fax: +91 1212439058

Received: 11 May 2012

Revised accepted: 5 February 2013

\begin{abstract}
Purpose: To develop a safe mucoadhesive gel for nasal drug delivery using okra polysaccharide. Methods: Rizatriptan benzoate nasal gel was developed using natural polysaccharide obtained from the Abelmoschus esculentus. The gel formulation was characterized for $\mathrm{pH}$, viscosity, mucoadhesion, and in vitro permeation. Permeation parameters obtained include drug flux (j), permeation coefficient $\left(k_{P}\right)$ and lag time $\left(t_{L}\right)$. The effect of sodium thioglycollate and sodium taurocholate on permeation of the gel formulations was evaluated using excised goat nasal mucosa.

Results: Okra gel formulation showed good properties in terms of $\mathrm{pH}$, viscosity and mucoadhesion. The drug was able to permeate through the goat nasal mucosa within $255 \mathrm{~min}$. The test okra nasal gel, with and without enhancer, showed superior permeation properties to gels prepared with synthetic polymers - hydroxylpropyl methylcellulose (HPMC) and sodium carboxymethyl cellulose (NaCMC). For example, drug flux (j) of okra nasal gel formulation and gel formulations made with HPMC and NaCMC was 134.8, 120.9 and 84.8, respectively.

Conclusion: Okra mucilage is a promising natural and safe gel former that can be developed to serve as an alternative to currently used synthetic gel formers for nasal drug delivery.
\end{abstract}

Keywords: Mucilage, Abelmoschus esculentus, Nasal gel, Rizatriptan, Permeation, Mucoadhesion

Tropical Journal of Pharmaceutical Research is indexed by Science Citation Index (SciSearch), Scopus, International Pharmaceutical Abstract, Chemical Abstracts, Embase, Index Copernicus, EBSCO, African Index Medicus, JournalSeek, Journal Citation Reports/Science Edition, Directory of Open Access Journals (DOAJ), African Journal Online, Bioline International, Open-J-Gate and Pharmacy Abstracts

\section{INTRODUCTION}

Delivery of drugs for local and systemic action through the nasal route has been recognized as an important and modern way for improvement of bioavailability. Rapid absorption of drug through the thin and porous nasal epithelium and low enzymatic degradation makes it a better alternative to oral and invasive routes. Needlefree delivery improves patient compliance with choice of self-medication. The drainage of formulation into nasopharynx through mucociliary clearance is the major drawback of nasal route of drug administration [1]. A variety of natural mucoadhesive gel forming plant polysaccharides have been identified which can minimize mucociliary clearance. These agents make intimate contact with the mucous layer, thereby enhancing the retention time of formulation in the nasal cavity and thus improve absorption and bioavailability [2-4].

Abelmoschus esculentus (Okra) has been identified as a plasma expander [5], diuretic and medicinal agent in dental disease [6]. Apart from physiological properties, the plant mucilage has 
also been identified as a binder for tablets [7]. Only a limited investigation of the applicability of the plant polysaccharide as a gel forming agent has been carried out so far; hence, the present work was designed to evaluate the acceptability of okra polysaccharides as a gel-forming agent for the safe and effective delivery of pharmaceuticals through the nasal route.

\section{EXPERIMENTAL}

\section{Materials}

Rizatriptan benzoate was received as a gift from Cipla, Raighar, Maharastra, India. All other ingredients used were of analytical grade and purchased from Central Drug Laboratory, New Delhi, India.

\section{Extraction of Okra mucilage}

Fresh fruits of okra $(1 \mathrm{~kg})$ were collected from the cultivated plant of farm fields from Meerut in the month of May. Fruits were authenticated by Dr Anjula Pandey (Principal Scientist) of National Bureau of Plant Genetic Resources, New Delhi. A voucher specimen (no. 4762) of the fruit was preserved in the herbarium of Meerut Institute of Engineering and Technology (MIET), Meerut for future reference. The fruits were washed with distilled water and the seeds removed by making a longitudinal incision. The fruits were cut into small pieces and homogenized using a mechanical blender (Ikon, Sunflame, Faridabad, India). The resultant mucilaginous material was stirred in $2 \mathrm{~L}$ of freshly prepared and cooled distilled water and $500 \mathrm{~g}$ of ice using a mechanical stirrer (RQ 20 Plus, Remi, Mumbai, India) at $1500 \mathrm{rpm}$ for $12 \mathrm{~h}$.

The mucilage was separated using a vacuum filter and precipitated with three times the volume of acetone. The precipitate was dried at $50{ }^{\circ} \mathrm{C}$ for
2 days in hot air oven (NAAY-M40, Naugra, Ambala, India) and stored in a desiccator with calcium carbonate as desiccant until used.

\section{Preparation of nasal gel}

Rizatriptan benzoate (200 mg) was dissolved in $10 \mathrm{ml}$ of nasal physiological solution (0.65\% $\mathrm{NaCl}, 0.04 \% \mathrm{KH}_{2} \mathrm{PO}_{4}, 0.09 \% \mathrm{~K}_{2} \mathrm{HPO}_{4}$, and 0.02 $\%$ benzalkonium chloride) at $\mathrm{pH}$ 6.2. The solution was sonicated in a bath sonicator (Lellasonic 50, Leela Electronics, Thane India) for $10 \mathrm{~min}$ until complete mixing of drug. The extracted okra mucilage (100 $\mathrm{mg})$ was added to the drug solution to obtain a $1 \% \mathrm{w} / \mathrm{v}$ dispersion. The resulting dispersion was stirred for complete hydration using a magnetic stirrer $(2 \mathrm{MLH}$, Remi, Mumbai, India) for $4 \mathrm{~h}$. The resulting gel was sealed and stored in a refrigerator until used.

The same method was used for the preparation of another batch of gel in which synthetic polymers - either hydroxypropyl methylcellulose (HPMC) or sodium carboxymethylcellulose (NaCMC) - were substituted for okra gel (Table 1).

\section{Determination of gel pH}

The $\mathrm{pH}$ of the formulations containing rizatriptan benzoate was measured using a digital $\mathrm{pH}$ meter (pH Tutor, Eutech Instrument, Singapore).

\section{Determination of gel viscosity}

The viscosity of the formulations was determined using a Brookfield R/S Plus Rheometer (cone and plate model). The measuring system used was C -25 Din, which is generally used for highly viscous liquids such as gums, mucilages and polymeric dispersions. Apparent viscosity was recorded at different rpm, ranging from $10-$ 100 at $37^{\circ} \mathrm{C}$.

Table 1: Composition of gel formulations

\begin{tabular}{|c|c|c|c|c|c|}
\hline Formulation code & $\begin{array}{c}\text { HPMC } \\
\text { (mg) }\end{array}$ & $\begin{array}{c}\text { NaCMC } \\
(\mathrm{mg})\end{array}$ & $\begin{array}{c}\text { Okra } \\
\text { mucilage } \\
(\mathrm{mg})\end{array}$ & $\begin{array}{c}\text { Sodium } \\
\text { taurocholate } \\
(\% w / v)\end{array}$ & $\begin{array}{c}\text { Sodium } \\
\text { thioglycollate } \\
(\% w / v)\end{array}$ \\
\hline HPMC 1 & 100 & - & - & - & - \\
\hline HPMC 2 & 100 & - & - & 0.50 & - \\
\hline HPMC 3 & 100 & - & - & - & 0.50 \\
\hline $\mathrm{Na} \mathrm{CMC} 1$ & - & 100 & - & - & - \\
\hline $\mathrm{Na} \mathrm{CMC} 2$ & - & 100 & - & 0.50 & - \\
\hline $\mathrm{Na} \mathrm{CMC} 3$ & - & 100 & - & - & 0.50 \\
\hline Okra 1 & - & - & 100 & - & - \\
\hline Okra 2 & - & - & 100 & 0.50 & - \\
\hline Okra 3 & - & - & 100 & - & 0.50 \\
\hline
\end{tabular}

Note: Total volume of nasal gel was $10 \mathrm{ml}$ and each formulation contained $200 \mathrm{mg}$ of rizatriptan benzoate 


\section{Evaluation of mucoadhesive strength}

The mucoadhesive strength of the formulations was evaluated using Park and Robinson method [9]. Excised goat nasal mucosa $\left(2.56 \mathrm{~cm}^{2}\right)$ was adhered on lower and upper probe of a modified balance. Nasal gel was placed between the mucosal layers and equilibrated at $37{ }^{\circ} \mathrm{C}$ for 15 $\mathrm{min}$. The force of adhesion $(\mathrm{N})$ and bioadhesive strength $(S)$ were determined from the minimum weight required to detach the mucosa from the formulation using Eqs 1 and 2.

$\mathrm{N}=m g / 1000$

where $m=$ weight required to detach the formulation from the nasal mucosa, and $g=$ acceleration due to gravity $\left(9.81 \mathrm{~m} / \mathrm{s}^{2}\right)$

$\mathrm{S}=\mathrm{N} / \mathrm{A}$

where $A$ is the mucous surface area exposed to the formulation

\section{In vitro permeation study}

In vitro drug release study was performed using the inverted test tube method [10]. A plastic tube of $8 \mathrm{~cm}$ height and $2.54 \mathrm{~cm}^{2}$ cross-sectional area for permeation was selected as a donor chamber. Goat nasal region was procured from the local slaughterhouse within $1 \mathrm{~h}$ of slaughtering the animal. Excised nasal mucosa was separated from the nose bone and tied carefully using a thread over the mouth of the tube. The tube was immersed in a beaker containing 100 $\mathrm{ml}$ of phosphate buffer ( $\mathrm{pH} \mathrm{6.8)}$, which served as the receptor chamber. The temperature was maintained $37 \pm 1{ }^{\circ} \mathrm{C}$ and the solution was stirred continuously using a magnetic starrier. Aliquots $(0.1 \mathrm{ml})$ were withdrawn at predetermined time intervals from the beaker, diluted, filtered and analyzed spectrophotometrically at $225 \mathrm{~nm}$ (UV 1700, Shimadzu, Japan).

The effect of $0.5 \% \mathrm{w} / \mathrm{v}$ enhancers - sodium taurocholate and sodium thioglycollate - on drug permeation was determined.

\section{Permeability data analysis}

A plot of \% cumulative drug permeation through nasal mucosa versus time was obtained. Values of steady state drug flux $(J)$, permeability coefficient $\left(K_{P}\right)$ and lag time $\left(t_{L}\right)$ were computed as per Eqs 3 and 4.

$\mathrm{J}=(\mathrm{dQ} / \mathrm{dt}) \mathrm{A}$

where $d Q$ is the change in the quantity of drug $(\mu g)$ permeated through nasal mucosa of surface area $\mathrm{A}\left(\mathrm{cm}^{2}\right)$ within time, $t(\mathrm{~min}) ; d Q / d t$ was obtained from the slope of the straight line portion of plot of drug permeation versus time.

Permeability coefficient $\left(K_{P}\right)=\mathrm{J} / \mathrm{CV}$

where $J$ is the drug flux and $C v$ the initial concentration of drug in the donor compartment
Lag time $\left(t_{L}\right)$ was calculated from the $x$-intercept of the slope at the steady state line of the curve.

\section{Statistical analysis}

Permeation data were expressed as mean \pm standard deviation (SD). One way analysis of variance (ANOVA) was applied to determine the significant differences between data using Sigmastat 2.03 software.

\section{RESULTS}

$\mathrm{pH}$

The $\mathrm{pH}$ of the gels prepared using okra mucilage, HPMC and NaCMC was 5.99, 6.40 and 6.27 , respectively.

\section{Viscosity}

The viscosity of the gels prepared from okra mucilage, HPMC and $\mathrm{Na} \mathrm{CMC}$ was in the range of 5.063 to $63.106,5.129$ to 48.228 and 5.497 to $63.164 \mathrm{mPas}$, respectively. In all cases, viscosity increased with decrease in rotation rate. The results show that the viscosity of okra based gel at $10 \mathrm{rpm}$, was significantly high $(p<0.001)$ as compared to that based on HPMC, but similar to the viscosity of that based on NaCMC (Figure 1).

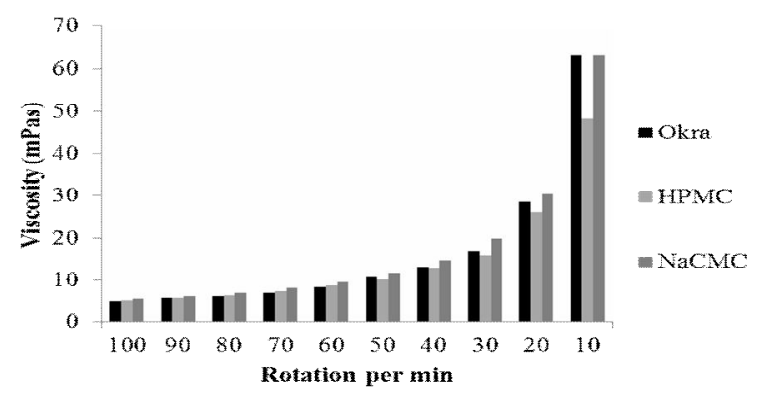

Fig 1: Viscosity of nasal gel formulations at different shear rates

\section{Mucoadhesive strength}

The mucoadhesive strength of the drug-loaded nasal gels are graphically represented in Figure 2. The results show that Okra mucilage gels possess nearly two times higher mucoadhesion than that of gel HPMC but similar strength to that of $\mathrm{NaCMC}$ gel.

\section{In vitro permeation}

The results indicate that nearly $100 \%$ of rizatriptan benzoate permeated from the gel prepared using mucilage of Okra in $255 \mathrm{~min}$, while for HPMC gel the same amount of drug 
permeated in 270 min. For NaCMC gel, $75 \%$ of drug permeated in 300 min (Figure 3).

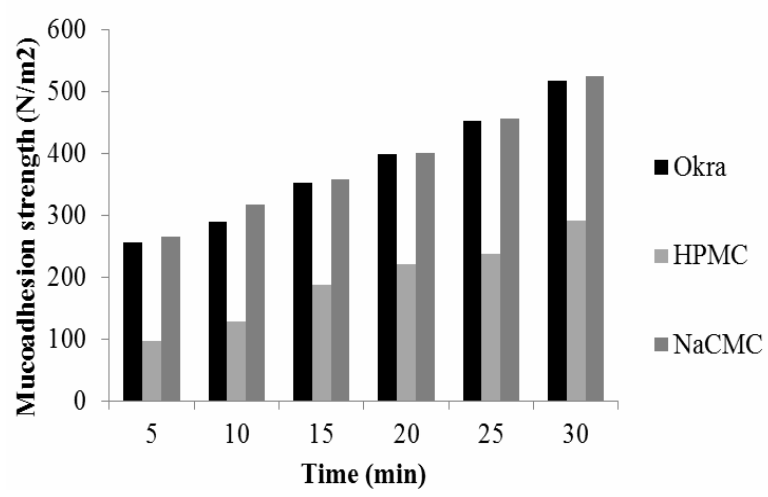

Fig 2: Mucoadhesive strength of nasal gel formulations at various contact times

Drug flux $(J)$ of HPMC, NaCMC and Okra gels was $120.86 \pm 0.79,84.77 \pm 1.84$ and $134.77 \pm$ $0.66 \mu \mathrm{g} / \mathrm{cm}^{2} \mathrm{~min}$, respectively. Similarly, the permeation coefficient $\left(\mathrm{K}_{\mathrm{p}}\right)$ of the gels was $(12.08$ $\pm 0.07) \times 10^{-3},(8.47 \pm 0.18) \times 10^{-3}$ and $(13.47 \pm$ $0.07) \times 10^{-3} \mathrm{~cm} / \mathrm{min}$, respectively (Table 2 ). The values of both parameters increased when permeation enhancers were incorporated in the gels.

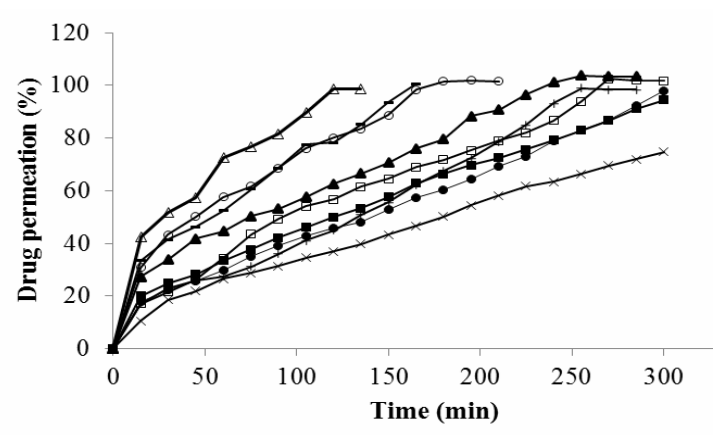

Fig 3: Comparative in vitro permeation of nasal gel of HPMC ( $\square$ ), HPMC + sodium taurocholate (०), HPMC + sodium thioglycollate $(\mathbf{\Delta}), \mathrm{NaCMC}(\times), \mathrm{NaCMC}+$ sodium taurocholate (a), NaCMC + sodium thioglycollate $(\bullet)$, okra $(+)$, okra + sodium taurocholate $(\Delta)$ and Okra + sodium thioglycollate $(-)$

Table 2: Permeation data (mean $\pm S D, n=3$ ) for nasal gel formulations

\begin{tabular}{lccc}
\hline $\begin{array}{l}\text { Formulation } \\
\text { code }\end{array}$ & $\begin{array}{c}\text { Drug flux } \\
(\boldsymbol{J}) \\
\left(\boldsymbol{\mu g} / \mathbf{c m}^{2} \mathbf{m i n}\right)\end{array}$ & $\begin{array}{c}\text { Permeability } \\
\text { coefficient } \\
\left(\boldsymbol{k}_{\boldsymbol{P}}\right) \mathbf{x ~ 1 \mathbf { 1 0 } ^ { - 3 }} \\
(\mathbf{c m} / \mathbf{m i n})\end{array}$ & $\begin{array}{c}\text { Lag time } \\
(\boldsymbol{t} \boldsymbol{L}) \\
(\mathbf{m i n})\end{array}$ \\
\hline HPMC 1 & $120.86 \pm 0.79$ & $12.08 \pm 00.07$ & $16.88 \pm 0.59$ \\
HPMC 2 & $160.23 \pm 6.69$ & $16.02 \pm 0.66$ & $30.43 \pm 1.06$ \\
HPMC 3 & $123.09 \pm 0.92$ & $12.3 \pm 0.09$ & $25.08 \pm 1.05$ \\
NaCMC 1 & $84.78 \pm 1.84$ & $8.47 \pm 0.18$ & $11.50 \pm 0.67$ \\
NaCMC 2 & $106.82 \pm 1.05$ & $10.68 \pm 0.105$ & $13.32 \pm 1.25$ \\
NaCMC 3 & $99.83 \pm 6.39$ & $9.94 \pm 0.63$ & $12.53 \pm 0.17$ \\
Okra 1 & $134.77 \pm 0.66$ & $13.47 \pm 0.07$ & $7.09 \pm 0.409$ \\
Okra 2 & $209.58 \pm 0.13$ & $20.95 \pm 0.013$ & $34.66 \pm 0.053$ \\
Okra 3 & $202.63 \pm 3.81$ & $20.26 \pm 0.38$ & $22.61 \pm 1.01$ \\
\hline
\end{tabular}

\section{DISCUSSION}

The $\mathrm{pH}$ of nasal gel is important because if the $\mathrm{pH}$ of the formulation is not within the range of nasal $\mathrm{pH}$, it may cause irritation to the nasal mucosa/tissue on application [11]. Since the normal $\mathrm{pH}$ of nasal cavity varies from 5.5 to 6.5 , all the nasal gels evaluated would be nonirritable to the nasal mucosa. The gel prepared from okra exhibited viscosity which was similar to those prepared with synthetic polymers indicating that the natural mucilage is suitable for nasal gel formulations.

Similarly, the mucoadhesive strength of the okra nasal gel was comparable to that of the synthetic polymers tested. Viscosity and mucoadhesive strength of the formulation affect the retention ability of the nasal cavity. Mucoadhesive strength increased proportionately with increasing contact time of the gel. This may be because by increasing contact time, more free chains of the mucoadhesive polymer becomes available which penetrate into the mucosa and exhibit higher rate of adhesion. Natural gels would be preferable to synthetic polymers since they would likely be safer.

Permeation data indicates that virtually $100 \%$ drug permeation was achieved with okra gel in 255 min without any permeation enhancer and that it was superior in this regard to the gels formulated with synthetic polymers. Drug permeation from nasal gel containing $\mathrm{NaCMC}$ as geling agent was least, which may be due to the inverse relation between drug release and viscosity. For drug molecules to permeate across the nasal epithelia they must first diffuse out of the formulation. Normally, drug release from hydrogel is governed by the diffusion. The apparent viscosity and polymeric chain complexity of the formulation influence diffusion of molecules [12].

Permeation of rizatriptan benzoate through nasal epithilia was clearly influenced by the types of gelling agent and permeation enhancer used. Okra nasal gel was influenced more by permeation enhancer (sodium taurocholate and sodium thioglychollate) than the synthetic gels tested. The reason may be that okra gel ensures easy availability of the enhancers for action on epithelial membrane by facilitating rapid release from the gel matrix, whereas synthetic polymers effect sustained release of enhancers in the same manner in the same way they do to drugs. Overall, okra mucilage seems a better alternative to the synthetic polymers for safe delivery of drug via nasal route. 
Both enhancers used in the present study are bile salts, and have been extensively employed to enhance drug permeation through epithilia. They are believed to act on both transcellular and paracellular pathways to enhance drug permeation. Their physiological role is related to solubilization and micellar entrapment of intracellular lipid which cause lipid emulsification and thus ensure easy passage of drug molecules. In addition, bile salts promote membrane fluidity and extraction of cellular protein [13].

\section{CONCLUSION}

The present study indicates that Abelmoschus esculentus mucilage gel is a potentially mucoadhesive material for delivery of drug via the nasal route. The data obtained demonstrate that this natural polymeric material possess good mucoadhesion and permeation chracteristics. Its biodegradable nature as well as likely low toxicity (since plant fruit is widely consumed as food) further supports its use as a suitable alternative to synthetic mucoadhesive polymers for nasal delivery. Further investigation, however, is required for complete elucidation of its safety and other characteristics.

\section{ACKNOWLEDGEMENT}

The authors are thankful to the management of MIET for financial assistance for the work, and also to Department of Biotechnology, MIET, Meerut, for providing instrumental support for the successful completion of the work.

\section{REFERENCES}

1. Ugwoke MI, Agu RU, Verbeke N, Kinget R. Nasal mucoadhesive drug delivery: Background, applications, trends and future perspectives. Adv Drug Delivery. Rev. 2005; 57: 1640-1665.

2. Kuotsu K, Bandyopadhayay AK, Development of oxytocin nasal gel using natural mucoadhesive agent obtained from the fruits of Dellinia indica. $L$. ScienceAsia. 2007; 33: 57-60.

3. Basu S, Chakrabotorty S, Bondyopadhayay AK. Development and evaluation of a mucoadhesive nasal gel of midazolam prepared with Linum usitatissimum L. seed mucilage. SciPharm. 2009; 77: 899-910.

4. Datta R, Bandhyopadhyay AK. A new drug delivery system for diazepam using natural mucoadhesive polysaccharide obtained from tamarind seeds. Saudi Pharmaceut J 2006; 14: 115-119.

5. Benjamin HR, Ihrig HK, Roth DA. The use of okra as a plasma replacement. Rev. Can. Biol. 1951; 10: 215-221.

6. Ndjouenkeu R, Goycoolea FM, Morris ER, Akingbala JO. Rheology of okra (Hibiscus esculentus L.) and dika nut (Irvingia gabonensis) polysaccharide. Carbohyd Polym. 1996; 29; 263-269.

7. Sinha VR, Kumria R. Binders for colon specific drug delivery, an in-vitro evaluation. Int. J. Pharm. 2002; 24: 923-931.

8. Katsutoshi H, Keiichiro E, Koji H. A convenient synthesis of lepidimoide from okra mucilage and its growthpromoting activity in hypocotyls. Carbohyd Res. 2004; 339: 9-19

9. Lee JW, Park JH, Robinson JR. Bioadhesive based dosage form: the next generation. J Pharm Sci. 2000; 89: 850-866.

10. Aukunuru J, Bonepally C, Guduri V. Preparation, Characterization and Optimization of Ibuprofen Ointment Intended for Topical and systemic delivery. Trop J Pharm Res. 2007; 6: 855-860.

11. Illum L, Fisher AN, Jabbal-Gill I. Bioadhesive starch microspheres and absorption enhancing agent act synergistically to enhance the nasal absorption of polypeptides. Int J Pharm. 2001; 222; 109-119.

12. Welin-Berger K, Neelissen JAM, Bergenstahl B. The effect of rheological behaviour of a topical anesthetic formulation on the release and permeation rates of the active compound. Eur $\mathrm{J}$ Pharm Sci; 2001; 13; 309-318.

13. Neuillez F. Factors and strategies for improving buccal absorption of peptides. Eur J Pharm Biopharm; 2001; 51; 93-109.

14. Senel S, Hincal AA. Drug permeation enhancement via buccal route: Possibilities and limitations. J Control Release. 2001; 72; 133-144. 